\title{
Proteomic basics - quantification and post-translational modifications of proteins: The 3rd European Summer School in Kloster Neustift
}

\author{
Katrin Marcus $^{a, *}$, Carla Schmidt ${ }^{b}$, Henning Urlaub $^{b}$ \\ ${ }^{a}$ Functional Proteomics, Medizinisches Proteom-Center, Ruhr-Universität Bochum, Bochum, Germany \\ ${ }^{b}$ Bioanalytical Mass Spectrometry Group, Max Planck Institute for Biophysical Chemistry, Göttingen, Germany
}

\section{A R T I C L E I N F O}

Article history:

Received 15 October 2009

Accepted 9 November 2009

Keywords:

Education

Proteomics

Quantification

Post-translational modifications

EuPA

Summer school

\begin{abstract}
A B S T R A C T
The field of proteomics is rapidly evolving and has emerged as a routine application in many laboratories. It covers not only the identification of proteins but also the quantification and analysis of post-translational protein modifications. During the last few years a series of summer schools teaching comprehensive knowledge in proteomic research and applied techniques have been held. Various research areas were dealt with by international experts in lectures and workshops. The summer schools were addressed to master's and graduate students as well as young post-docs currently moving into the field of proteomics. Here, we give a report on the third European Summer School "Quantification and Post-translational Modifications of Proteins" held at the monastery in Neustift, Brixen/Bressanone, South Tyrol, Italy from August 2 to 9, 2009.
\end{abstract}

The field of proteomics has gained importance in recent years. Proteomic and associated technologies have become indispensable tools in molecular, cellular and systems biology. These techniques allow the analysis of highly complex protein mixtures and can thus lead to an understanding of cellular processes and to the identification of disorders associated with various diseases. Although protein identification is performed on a routine basis in many laboratories, reproducible sample preparation, reliable quantification, detection of post-translational modifications, and detection of protein-protein and protein-ligand interactions are far from being routine issues. A profound understanding of principles and methods is required to successfully apply, optimise and develop methods for proteome studies. Therefore young scientists and newcomers

\footnotetext{
* Corresponding author.

E-mail address: Katrin.Marcus@rub.de (K. Marcus).
}

in the field of proteomics should be well trained in the theoretical and practical basics of their research.

For these reasons, in 2004 a series of summer schools in "Proteomic Basics" (www.proteomic-basics.eu) were launched. At first (2004-2006) the summer school was held only for German students as an initiative within the programme framework "Modern Methods of Protein Analysis" supported by the German Federal Ministry for Education and Research (BMBF). In 2007, the summer school opened up for graduate students and post-docs from all European countries [1,2]. The German Volkswagen Foundation has provided a sound financial basis for a European summer school series for the past three years. Additionally, the European Summer School has received whole-hearted support from the European Proteome Association (EuPA), and almost all national proteome societies provided funding for stipends to the successful applicants to participate in the summer schools. Each summer school was designed to build on the previous ones, while at the same time retaining the "basics" character of the 
course. The focus of the three European summer schools was on "Sample Preparation and Separation" (2007), "Protein Identification - Mass Spectrometry" (2008), and "Quantification and Posttranslational Modifications of Proteins" (2009).

The organisers - Katrin Marcus, from the Medizinisches Proteom-Center Bochum, of the Ruhr-Universität Bochum; Henning Urlaub, from the Max Planck Institute for Biophysical Chemistry, Göttingen; and the co-organiser Carla Schmidt from the same institute invited 65 master's and graduate students, post-docs and technical assistants to this year's summer school, which focussed on "Quantification and Post-translational Modifications of Proteins". Since the number of applicants (about 110) greatly exceeded the number of places available, the number of participants was increased to 65 at short notice. In the end, 64 participants from all over Europe came to Kloster Neustift, Brixen/Bressanone, South Tyrol, Italy to attend the week-long course (Fig. 1). The course's international character was enhanced by the participation of 12 outstanding speakers and company representatives from Austria, Denmark, England, France, Germany, Italy, the Netherlands, and Norway (Fig. 2).

Ole N. Jensen (University of Southern Denmark, Odense, Denmark) opened the Summer School with a plenary lecture about "Adventures in Proteomics". He presented a survey of ongoing research projects in which advanced mass spectrometry was used to identify, quantify, and characterise proteins from several different organisms. The focus of his lecture was on the mapping and quantification of post-translational modifications of proteins [3] and thus provided an ideal startup for the sessions that were to follow.

The first two lectures covered quantification by 2-D electrophoresis and the reduction of the most abundant proteins in a sample. Thierry Rabilloud (CEA, Grenoble, France) described and critically analysed the most widely used detection methods [4-6], and Pier Giorgio Righetti introduced the "ProteoMiner Technology" [7], an approach allowing the capture of all species present

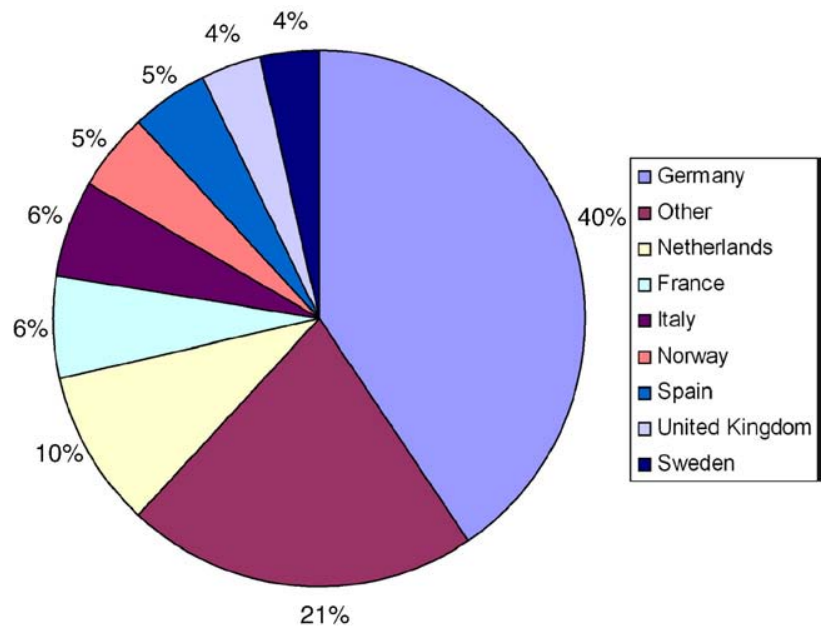

Fig. 2 - Participants from almost all European countries came to Kloster Neustift, Brixen/Bressanone, South Tyrol, Italy to attend the third European Summer School. The international character was enhanced by the participation of 12 outstanding speakers and company representatives. The distribution of participants from different European countries (including speakers, company representatives, and organisers) is shown in a pie chart. Countries with more than 3 participants are listed. Countries with less than three participants are combined in "other" (participants from Austria, Belgium, Czech Republic, Denmark, Estonia, Finland, Greece, Hungary, Poland, Portugal, and Switzerland).

in a proteome, but at much reduced protein concentration differences.

In the following lectures the analysis of various posttranslational modifications (PTMs) was discussed. Karl Mechtler (Research Institute of Molecular Pathology, Wien, Austria)

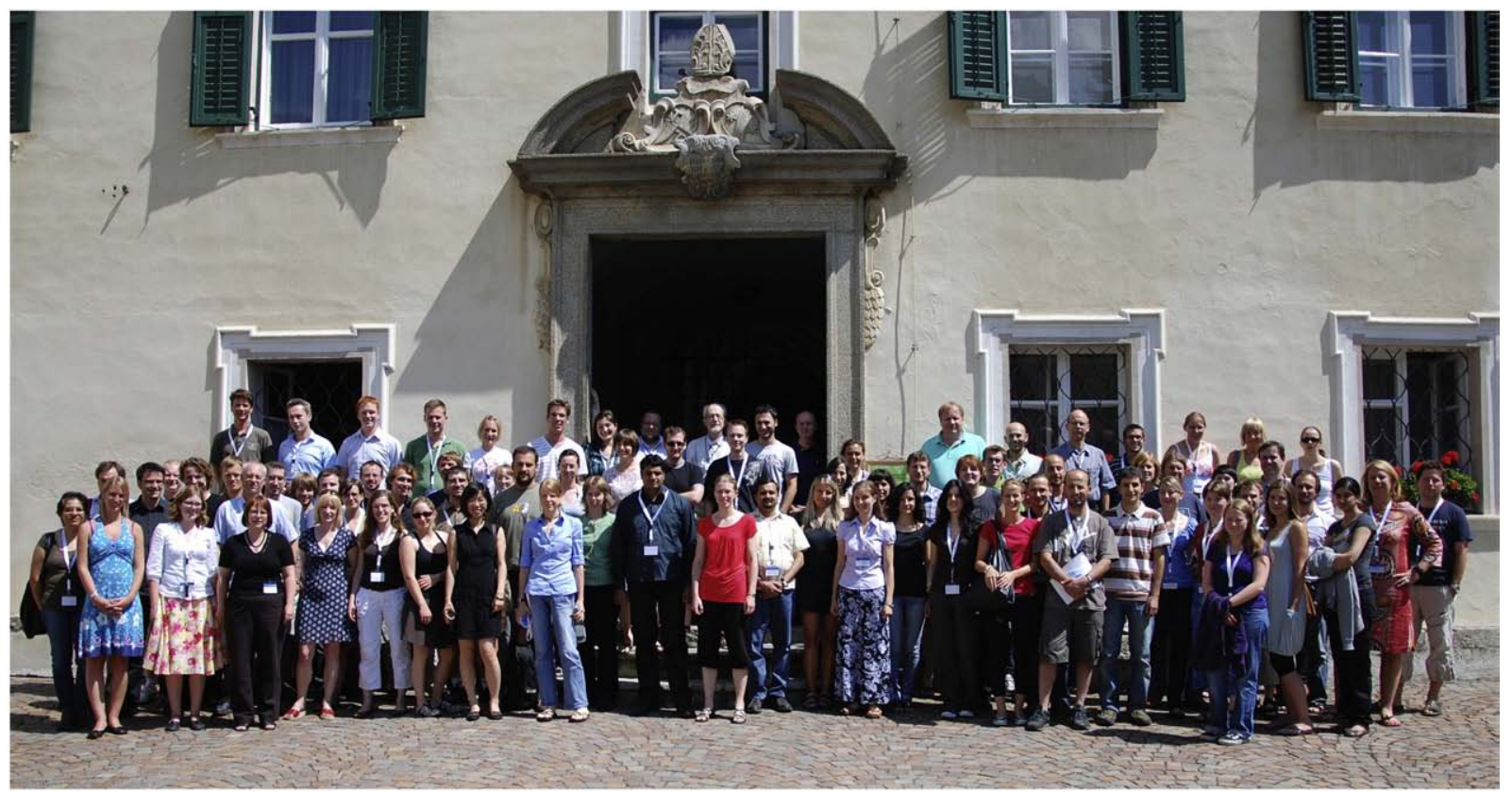

Fig. 1 - Participants, speakers, and organisers of the third European Summer School in "Quantification and Post-translational Modifications of Proteins". 
presented several enrichment methods and mass-spectrometry techniques for the analysis of phosphopeptides [8-10], Carolin Huhn and Renee Ruhaak (Leiden University Medical Center, Leiden, The Netherlands) gave a survey of the most important analytical techniques applied to the analysis of glycosylated proteins [11,12], and Angela Bacchi (San Raffaele del Monte Tabor Foundation, Milan, Italy) focused on PTMs in redox proteomics, in particular state-of-the-art techniques for the analysis of nitric-oxide-induced S-nitrosylation [13,14]. Oliver Pötz (NMI, University of Tübingen, Reutlingen, Germany) completed this part of the programme with a lecture about targeted phosphorylation analysis by immunoaffinity-based proteomics [15].

The second part of the programme covered various labelling and quantification techniques, mainly for the MS-based quantification of proteins. In this part, Bernd Thiede (University of Oslo, Norway) started with an overview of different principles of labelling and quantification techniques by MS [16-23]. Out of these, metabolic labelling $[16,24]$ was explained in more detail by Jeroen Krijgsveld (EMBL Heidelberg, Germany). Bernhard Küster discussed the pros and cons of the more widely used chemical labelling strategies (for review see ref. [25]), and Bettina Warscheid (Medizinisches Proteom-Center Bochum, Ruhr-Universität Bochum, Germany) introduced alternative methods for MS-based quantification (e.g. refs. [26-29]).

Matthias Selbach (MDC, Berlin, Germany) presented the MaxQuant software for data analysis of SILAC-based proteome studies [30,31]. His lecture about "MaxQuant and statistical analysis of large scale datasets" included a preview of the next Summer School, which will focus on statistics and data analysis.

In addition to the above-mentioned scientific lectures, company representatives from Applied Biosystems, Bruker Daltonics, Thermo Fisher Scientific, and Waters gave in-depth lectures on technical applications and latest developments. With lectures about "relative and absolute quantification of proteins by multiple reaction monitoring" (Christof Lenz, Applied Biosystems, Germany), "electron transfer dissociation (ETD) versus CID for the analysis of post-translational modifications" (Marcus Macht, Bruker Daltonics, Germany), "the LTQ Orbitrap - instrument basics, new developments and selected proteomics applications" (Kai Scheffler, Thermo Fisher Scientific, Germany), and "a high definition quantitative LC/MS strategy for unbiased discovery and targeted proteomics" (Mark A. McDowall, Waters, United Kingdom) the scientific programme of the Summer School was perfectly complemented.

The more interactive parts of the summer school were the two workshops. Every participant could choose two workshops of his or her interest. In total, five different workshops were available: (i) gel-based quantification and detection of PTMs, (ii) MS-based detection of PTMs, (iii) MS-based quantification, (iv) MaxQuant workshop, and (v) spectra interpretation and annotation. The workshops were supervised by the speakers and were designed differently - exercises, presentations and "question time" are only some examples. All the workshops offered enjoyed great popularity reflecting the strong motivation of the participants.

The scientific programme also included two poster sessions, which provided the participants with the possibility of discussing

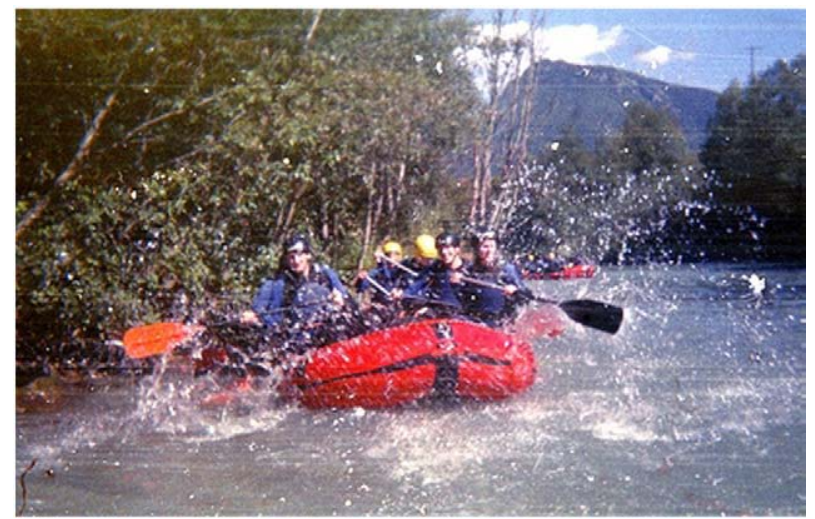

Fig. 3 - The scientific programme of the Summer School was completed by several social events which added to the very open and communicative atmosphere.

their own research projects with experts and other young scientists. The high quality of the presented posters and the persistence in discussing scientific questions were remarkable. For that reason, the number of poster prizes was increased at short notice from two to four. This year, the poster prizes were awarded to Violet Gautier (IPBS-CNRS, Toulouse, France), Rieuwert Hoppes (Netherlands Cancer Institute, Amsterdam, Netherlands), Marit Terweij (Netherlands Cancer Institute, Amsterdam, Netherlands), and Sonja Volk (NMI, Reutlingen, Germany). All poster prize-winners received a one-year subscription to the journal Nature.

It remains to be observed that, in addition to the scientific programme, diverse social activities were scheduled. A hiking tour, wine-tasting, the traditional soccer game, and rafting, mountain biking, climbing and sight-seeing in town added to the very open and communicative atmosphere (Fig. 3). All in all, the summer school was a very intensive scientific exchange of views and experiences. All participants returned home highly motivated to turn the ideas they had heard of during the week into reality.

Although the financial support of the German VW Foundation ended with the third European Summer School, the organisers are highly encouraged to organise a fourth European Summer School. It will focus on data analysis and statistics and will be held from August 1 to 7, 2010, again in Kloster Neustift. The organisers look forward to meeting next year's participants!

\section{Acknowledgment}

The EU Summer School "Proteomic Basics" is largely supported by a grant from the German VW Foundation to K.M. and H.U.

\section{R E F E R E N C E S}

[1] Marcus K, Kuhn-Holsken E, Schmidt C, Schulenborg T, Urlaub H. 'Proteomic basics-sample preparation and separation': the 1st European Summer School in Kloster Neustift, 12-18 August, 2007 Brixen/Bressanone, South Tyrol, Italy.

Proteomics 2008;8:230-3. 
[2] Collins ES, Little SJ. The 1st European Summer School on 'proteomic basics'-the students view. 12-18 August, 2007 Kloster Neustift, Brixen/Bressanone, South Tyrol, Italy. Proteomics 2008;8:234-6.

[3] Jensen ON. Interpreting the protein language using proteomics. Nat Rev Mol Cell Biol 2006;7:391-403.

[4] Miller I, Crawford J, Gianazza E. Protein stains for proteomic applications: which, when, why? Proteomics 2006;6:5385-408.

[5] Chevalier F, Centeno D, Rofidal V, Tauzin M, Martin O, Sommerer N, Rossignol M. Different impact of staining procedures using visible stains and fluorescent dyes for large-scale investigation of proteomes by MALDI-TOF mass spectrometry. J Proteome Res 2006;5:512-20.

[6] Chevallet M, Luche S, Rabilloud T. Silver staining of proteins in polyacrylamide gels. Nat Protoc 2006;1:1852-8.

[7] Boschetti E, Righetti PG. The ProteoMiner in the proteomic arena: a non-depleting tool for discovering low-abundance species. J Proteomics 2008;71:255-64.

[8] Mazanek M, Mituloviae G, Herzog F, Stingl C, Hutchins JR, Peters JM, Mechtler K. Titanium dioxide as a chemo-affinity solid phase in offline phosphopeptide chromatography prior to HPLC-MS/MS analysis. Nat Protoc 2007;2:1059-69.

[9] Stingl C, Ihling C, Ammerer G, Sinz A, Mechtler K. Application of different fragmentation techniques for the analysis of phosphopeptides using a hybrid linear ion trap-FTICR mass spectrometer. Biochim Biophys Acta 2006;1764:1842-52.

[10] Schmidt A, Csaszar E, Ammerer G, Mechtler K. Enhanced detection and identification of multiply phosphorylated peptides using TiO2 enrichment in combination with MALDI TOF/TOF MS. Proteomics 2008;8:4577-92.

[11] Huhn C, Selman MH, Ruhaak LR, Deelder AM, Wuhrer M. IgG glycosylation analysis. Proteomics 2009;9:882-913.

[12] Wuhrer M, Catalina MI, Deelder AM, Hokke CH. Glycoproteomics based on tandem mass spectrometry of glycopeptides. J Chromatogr B Analyt Technol Biomed Life Sci 2007;849:115-28.

[13] Camerini S, Polci ML, Bachi A. Proteomics approaches to study the redox state of cysteine-containing proteins. Ann Ist Super Sanita 2005;41:451-7.

[14] Di Girolamo F, Campanella L, Samperi R, Bachi A. Mass spectrometric identification of hemoglobin modifications induced by nitrosobenzene. Ecotoxicol Environ Saf 2009;72:1601-8.

[15] Templin MF, Stoll D, Schwenk JM, Pötz O, Kramer S, Joos TO. Protein microarrays: promising tools for proteomic research. Proteomics 2003;3:2155-66.

[16] Ong SE, Blagoev B, Kratchmarova I, Kristensen DB, Steen H, Pandey A, Mann M. Stable isotope labeling by amino acids in cell culture, SILAC, as a simple and accurate approach to expression proteomics. Mol Cell Proteomics 2002;1:376-86.

[17] Miyagi M, Rao KC. Proteolytic 180-labeling strategies for quantitative proteomics. Mass Spectrom Rev 2007;26:121-36.

[18] Yi EC, Li XJ, Cooke K, Lee H, Raught B, Page A, et al. Increased quantitative proteome coverage with (13)C/(12)C-based, acid- cleavable isotope-coded affinity tag reagent and modified data acquisition scheme. Proteomics 2005;5:380-7.

[19] Chakraborty A, Regnier FE. Global internal standard technology for comparative proteomics. J Chromatogr A 2002;949:173-84.

[20] Schmidt A, Kellermann J, Lottspeich F. A novel strategy for quantitative proteomics using isotope-coded protein labels. Proteomics 2005;5:4-15.

[21] Koehler CJ, Strozynski M, Kozielski F, Treumann A, Thiede B. Isobaric Peptide Termini Labeling for MS/MS-Based Quantitative Proteomics. J Proteome Res 2009;8:4333-41.

[22] Ross PL, Huang YN, Marchese JN, Williamson B, Parker K, Hattan S, et al. Multiplexed protein quantitation in Saccharomyces cerevisiae using amine-reactive isobaric tagging reagents. Mol Cell Proteomics 2004;3:1154-69.

[23] Thompson A, Schafer J, Kuhn K, Kienle S, Schwarz J, Schmidt $G$, et al. Tandem mass tags: a novel quantification strategy for comparative analysis of complex protein mixtures by MS/MS. Anal Chem 2003;75:1895-904.

[24] Oda Y, Huang K, Cross FR, Cowburn D, Chait BT. Accurate quantitation of protein expression and site-specific phosphorylation. Proc Natl Acad Sci U S A 1999;96:6591-6.

[25] Bantscheff M, Schirle M, Sweetman G, Rick J, Kuster B. Quantitative mass spectrometry in proteomics: a critical review. Anal Bioanal Chem 2007;389:1017-31.

[26] Liu T, Qian WJ, Strittmatter EF, Camp 2nd DG, Anderson GA, Thrall BD, Smith RD. High-throughput comparative proteome analysis using a quantitative cysteinyl-peptide enrichment technology. Anal Chem 2004;76:5345-53.

[27] Zybailov B, Mosley AL, Sardiu ME, Coleman MK, Florens L, Washburn MP. Statistical analysis of membrane proteome expression changes in Saccharomyces cerevisiae. J Proteome Res 2006;5:2339-47.

[28] Ishihama Y, Oda Y, Tabata T, Sato T, Nagasu T, Rappsilber J, Mann M. Exponentially modified protein abundance index (emPAI) for estimation of absolute protein amount in proteomics by the number of sequenced peptides per protein. Mol Cell Proteomics 2005;4:1265-72.

[29] Braisted JC, Kuntumalla S, Vogel C, Marcotte EM, Rodrigues AR, Wang R, et al. The APEX Quantitative Proteomics Tool: generating protein quantitation estimates from LC-MS/MS proteomics results. BMC Bioinformatics 2008;9:529.

[30] Cox J, Mann M. MaxQuant enables high peptide identification rates, individualized p.p.b.-range mass accuracies and proteome-wide protein quantification. Nat Biotechnol 2008;26:1367-72.

[31] Cox J, Matic I, Hilger M, Nagaraj N, Selbach M, Olsen JV, Mann M. A practical guide to the MaxQuant computational platform for SILAC-based quantitative proteomics. Nat Protoc 2009;4:698-705. 